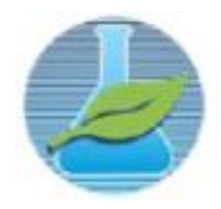

ol. 03 N. 01 (2017) 049-051
JCEC/REQ ${ }^{2}$

Journal

ISSN: 2446-9416

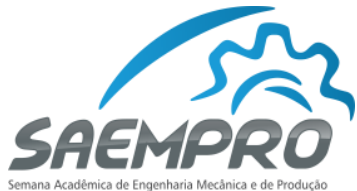

\author{
"EU, A INDÚSTRIA E O MUNDO" \\ 08 a 11 de novembro de 2016 no campus Viçosa da UFV \\ Departamento de Engenharia de Produção e Mecânica - DEP \\ Universidade Federal de Viçosa - UFV
}

\title{
ESTUDO DE CASO: O MAPEAMENTO DE PROCESSOS NO SETOR DE FATURAMENTO DE UM HOSPITAL
}

\author{
Francisco Eduardo Gomes Cardoso, Luzmarina Kasten Viana \\ Universidade Federal de Viçosa, Departamento de Engenharia de Produção e Mecânica \\ $\mathrm{Ph}$. Rolfs s/n - 36570-000 - Viçosa - MG \\ francisco.cardoso@ufv.com; luzmarina.viana@ufv.br
}

\section{INTRODUÇÃO}

A fim de satisfazer as necessidades das partes interessadas é essencial que as organizações busquem adotar as melhores práticas de gestão, promovendo uma estratégia eficiente em que os processos estejam bem alinhados com a razão de ser principal do negócio. Essa afirmativa é válida tanto para organizações privadas quanto para instituições públicas e filantrópicas, como é o caso que será apresentado no presente trabalho.

Este resumo é baseado no projeto desenvolvido pela ONG Engenheiros Sem Fronteiros, em um hospital da Zona da Mata mineira, que é uma associação civil de direito privado, com caráter assistencial, sem fins lucrativos. Neste trabalho será exposto como foi desenvolvido o projeto no setor de Faturamento do hospital. Além desse setor, os seguintes setores foram trabalhados: portaria, recepção, triagem, raio-X, almoxarifado, maternidade e apartamentos.

$\mathrm{O}$ faturamento, considerado um setor muito crítico do hospital, tem por objetivo elaborar as faturas dos procedimentos realizados de cada paciente atendido, ou seja, para cada paciente atendido na instituição, deve ser elaborada uma fatura cobrando dos convênios os valores gastos dentro de um prazo estabelecido por contrato, uma vez que, sem essas cobranças, os convênios não pagam pelos procedimentos realizados. As fontes de receita do hospital são advindas do SUS e dos convênios, sendo que o SUS paga um valor fixo mensal ao hospital, independentemente do número de procedimentos realizados e os convênios pagam pelos procedimentos efetuados.

Dentro dessa vertente, existem duas formas possíveis para realizar o faturamento dos pacientes que receberam alta: as cobranças advindas da internação e da emergência. Todos os faturistas do setor possuem muito tempo de experiência no cargo e sabem executar as suas tarefas de forma precisa. Contudo, a grande dificuldade encontrada foi a ausência de um controle sistemático das perdas em relação aos valores recebidos (valores glosados).

Glosa significa a supressão (eliminação) total ou parcial dos valores descritos na fatura que, em tese, deveria ser recebido pelo hospital dos convênios. Isso acontece pelo fato de que quando esses documentos passam pela auditoria dos convênios, o convênio tem por direito não realizar o pagamento dos itens que não são devidamente descritos. Tais glosas geram um impacto negativo (perda de capital) que não era medido pelo hospital.

As glosas causavam uma grande preocupação aos funcionários do setor, uma vez que eles possuem uma noção básica dos motivos que as geram, mas não conseguem elaborar uma medida efetiva para melhorar o desempenho do setor. Segundo eles, as causas da maioria das glosas são oriundas de outros setores, como por exemplo: falta de checagem no setor de enfermagem (enfermeiros), falta de assinatura do médico (médicos), falta de assinatura dos pacientes (recepcionistas), validade do cartão do convênio vencida (recepcionistas), dentre outros. Todavia, o 
problema pode também estar ligado ao setor, como a incompatibilidade entre os valores das tabelas de preço do convênio e do hospital, ou seja, o sistema do hospital pode estar desatualizado.

A principal dificuldade gerada para o controle do trabalho dos faturistas é o fato de que eles podem estar sistematicamente faturando os prontuários e ETEs de forma errada, não sendo possível a identificação desses erros. Tais erros podem ocorrer por desconhecimento de algum procedimento, negligência, ou mudança no procedimento de cobrança do convênio.

\section{OBJETIVOS}

O presente trabalho objetivou mapear os processos críticos dos setores do hospital, no intuito de possibilitar maior eficiência das atividades de maior valor agregado, melhor treinamento para os funcionários e de garantir maior conhecimento para a administração a respeito do funcionamento dos departamentos do hospital. Dessa forma, o projeto visava promover o redesenho e a melhoria dos processos, proporcionando uma gestão racional, sistemática e integrada do hospital.

\section{METODOLOGIA}

Gestão por processos é, de acordo com DeToro e McCabe (1997), "uma estrutura gerencial orientada a processos, em que gestor, time e executores do processo são todos executores e pensadores enquanto projetam seu trabalho, inspecionam seus resultados e redesenham seu sistema de trabalho para alcançar melhores resultados". Com o Mapeamento de Processos, o hospital, que atuava de forma funcional e fragmentada, deve passar a orientar-se por processos e integrar toda a instituição.

Em uma parte preliminar ao projeto, foram definidas as atividades mais críticas pela equipe administrativa e a coordenadora de qualidade do hospital. Após essa definição, os consultores do projeto se dividiram em equipes ( 3 duplas) para realizarem o mapeamento. A primeira parte do projeto foi a realização do diagnóstico e mapeamento do setor de faturamento do hospital. Inicialmente realizou-se uma reunião com o coordenador de tal setor, que elucidou o seu funcionamento, apontou os problemas considerados mais sérios e entregou um documento com a descrição de cargos e os nomes de seus respectivos ocupantes. Em seguida, cada colaborador foi apresentado à equipe do projeto, sendo explicado o propósito do projeto e pedindo a colaboração de todos, fornecendo toda informação necessária para realização do mapeamento.

Os dados necessários para realização do mapeamento de todos os processos foram coletados por meio de observações através do acompanhamento dos funcionários e entrevistas semiestruturadas com os funcionários responsáveis por cada atividade. A análise das atividades foi realizada por meio de reuniões com a equipe técnica responsável pelas atividades e a equipe administrativa do hospital. Para realizar o mapeamento das atividades, compreender seu funcionamento e os recursos nele envolvidos, foram elaborados os Procedimentos Operacionais Padrões (POPs), um fluxograma para indicar a relação entre os diferentes macro-processos e, paralelamente a isso, foi construído uma tabela com a identificação de pontos passíveis de melhoria e suas respectivas sugestões para solucioná-los.

A segunda parte do projeto, denominada desenvolvimento, foi a definição de quais eram as ações para que o redesenho dos processos fosse realizado, além da definição das mudanças no fluxo das atividades, como alterações na ordem e/ou exclusão de algumas atividades. Na terceira parte do projeto executou-se o que foi definido no desenvolvimento. Durante esta etapa, foram apresentados o fluxograma das atividades e os instrumentos que irão auxiliar no controle gerencial como formulários, normas e indicadores de desempenho. Na quarta e última parte do projeto foi realizado o acompanhamento das atividades para verificar que os processos estavam sendo executados em conformidade com o que foi redesenhado. Realizou-se, então, o acompanhamento dos processos críticos mapeados para avaliar se as atividades estavam sendo cumpridas conforme especificado nos padrões desenvolvidos (POPs). 


\section{RESULTADOS}

Ao se desenvolver todas as etapas do projeto, foram criados 11 POPs para o setor do faturamento, de acordo com o padrão que deveria ser executado para faturar cada convênio específico ou grupo de convênios.Foi elaborado também um fluxograma indicando todos os macros processos, segmentando os responsáveis pela execução em cada processo. Esse fluxograma teve por objetivo indicar o fluxo de movimentação do processo de faturar cada prontuário e ETE, desde o momento que chega no setor até o momento que é emitida a fatura, permitindo o maior entendimento acerca dos procedimentos realizados.

Em paralelo ao desenvolvimento do projeto, foi criada uma tabela com 13 pontos passíveis de melhoria, que posteriormente foi apresentada ao coordenador do setor e aos gestores do hospital para discussão e análise dos pontos levantados. Diante do principal problema apresentado no início do projeto, o desenvolvimento do trabalho permitiu mostrar que o motivo que inviabilizava a elaboração de medidas para minimizar os valores glosados era o hospital não possuir uma ferramenta que quantificasse e estratificasse as principais causas de glosa. Para solucionar tal problema, foi implementado um indicador para mensurar o valor e as causas dessas glosas utilizando o software Excel com extensão do Visual Basic. Dessa forma, foi possível criar uma planilha de forma organizada coletando todos os dados necessários e gerando automaticamente os indicadores, através de gráficos e tabelas dinâmicas, que posteriormente deverão ser analisados para identificar as causas fundamentais das glosas e subsequente elaboração de ações de melhorias, possibilitando aos gestores melhorar continuamente seus processos.

\section{CONCLUSÕES}

O objetivo do trabalho proposto foi alcançado com êxito, trazendo como benefícios à organização trabalhada, através dos POPs, ITs, fluxograma, proposições de melhoria e o indicador de desempenho, o maior entendimento das atividades, uma visualização mais clara das responsabilidades e quem são os tomadores de decisão, a identificação dos gargalos e retrabalhos, a facilitação da realização de treinamentos.

O comprometimento do líder do setor com o projeto facilitou o trabalho dos consultores e, consequentemente, os resultados satisfatórios obtidos. Contudo, ainda houve uma resistência grande por parte dos colaboradores entrevistados para explicar detalhadamente as suas rotinas de trabalho, o que sugere que a conscientização acerca da importância do projeto poderia ser trabalhada de outras formas complementares à utilizada. Outro aspecto importante é a necessidade de identificar os processos críticos, bem como o relacionamento destes com outros processos e, para isso, é fundamental ter indicadores de desempenho e uma visão holística da organização para mensurar e estratificar todos os problemas e, então, priorizar onde serão realizadas melhorias.

Como sugestão de futuro trabalho a ser realizado no hospital, pode-se elencar um projeto que vise efetuar a etapa de controle e captura dos resultados, ou seja, realizar o acompanhamento da utilização da ferramenta construída. Isso significa utilizar os dados que a planilha disponibiliza a respeito das causas raízes das glosas no setor de faturamento para elaborar contramedidas no sentido de bloquear estas causas, objetivando diminuir o percentual de contas glosadas. Esta análise das causas raízes pode inclusive indicar a necessidade de alguma alteração de processo no setor de faturamento ou em outros setores do hospital, o que demandaria mapear outros departamentos que ficaram fora do escopo do presente trabalho.

\section{REFERÊNCIA}

DETORO, I.; MCCABE, T. "How to stay flexible and elude fads". Quality Progress, Milwaukee, v.30, n.3, p. 55-60, 1997. 